\title{
Magnetic distortion of GDS transfer functions: An example from the Penninic Alps of Eastern Switzerland revealing a crustal conductor
}

\author{
Marcus Gurk \\ Institute of Geology, CH-2000 Neuchâtel, Switzerland \\ (Received November 2, 1998; Revised April 12, 1999; Accepted April 12, 1999)
}

\begin{abstract}
We carried out sixty-four MT and GDS soundings in the eastern Swiss Alps to obtain information on the electrical conductivity distribution. One of the main findings is an anomalous directional behaviour of the real induction arrows over the entire period range $(T=1-300 \mathrm{~s})$ on the Bündnerschiefer. The Bündnerschiefer occurs between the crystalline Aar and Gotthard massives to the North and the crystalline Penninic nappes (Adula, Tambo, Suretta) to the South within the investigation area. The sediments form an elongated eastwards plunging ramp with a possible conductive link to the Northern Swiss Permo-carboniferous trough (Molasse basin). We consider electric currents induced in various local and regional conductive structures and leaking into the Bündnerschiefer as possible causes for the observed effect upon the electromagnetic field. Applying Hypothetical Event Analysis (HEA) we find a spatial decoupling of the induction processes with depth and a conductivity anomaly presumably due to the northward indentation by the Adriatic plate.
\end{abstract}

\section{Introduction}

Based on the available seismic, gravimetric and geologic data from the past years, our understanding of the deep structure of the Central Alps has been revised. This part of the alpine mountain belt was formed during the Late Cretaceous and Pliocene (Schmid et al., 1996) by the collision of the European and Adriatic continents. Various long and short seismic profiles together with information from geologic field and laboratory studies have been projected on three major traverses across the Western and Central Alps (Pfiffner and Hitz, 1997). The E1 (Eastern Traverse) profile is part of the European Geotraverse conducted from the active Mediterranean margin to the Precambrian shield in Scandinavia (Blundell et al., 1992). The aim of the combined interpretation of geophysical and geological information (Schmid et al., 1996), was to elucidate the regional mechanisms involved in the building of the Alps. Close to this line about sixty-four MT and GDS sites with a spacing of about $5 \mathrm{~km}$ measured the natural magnetic and telluric variations in a period range from $T=1-300 \mathrm{~s}$. We suggested to search structural and geometrical correlations of well defined series within the Bündnerschiefer to provide additional information about the three-dimensional structure of the upper and lower crust, as well as to reveal similarities or differences in the conductivity distribution of the western and eastern Penninic Alps. However, the initial results show anomalous directional behaviour of the real parts of the induction arrows derived from the GDS data. Similar observations have been documented in several field examples over elongated conductive structures (Arora and Adam, 1992). Generally, we address our observation

Copy right (C) The Society of Geomagnetism and Earth, Planetary and Space Sciences (SGEPSS); The Seismological Society of Japan; The Volcanological Society of Japan; The Geodetic Society of Japan; The Japanese Society for Planetary Sciences. to the distortion effect due to the three-dimensional tectonic setting of the conductive structures in the upper and lower crust. Locally, we suspect near-surface inhomogeneities to cause current channelling and/or deflection which is likely to affect the directions of the induction arrows. In this case, the regional electrical strike determined from single site MT data for the computation of reliable TE and TM mode impedances might be misleading (Bahr, 1988; Jones and Groom, 1993).

\section{Geological Settings}

Figure 1 is a map of Switzerland, containing the surveyed area. Figure 2 shows a simplified North-South profile across the eastern Central Alps from the Molassse foredeep to the South Alpine thrust belt crosscutting the three main domains (Coward and Dietrich, 1989). From North to South we find (Fig. 3):

- an external part (Helvetic Aar and Gotthard Massives), followed by

- the Penninic Zone and

- South Alpine Units.

The Penninic Zone consists of imbricate stacks of sedimentary cover and basement slices, including the mesozoic Bündnerschiefer, Avers-Schiefer and the crystalline microcontinents Adula, Tambo and Suretta. Together with ophiolithic rocks they form the remnant of the alpine Thetys, which has been divided by deep sea swells into different pullapart basins. In one of these basins, the Bündnerschiefer was deposited as turbidity currents. During Tertiary time the intrusion of the Bregaglia massive (30 Ma) took place along the Insubric Line forming the southernmost border of the investigation area. To the East we find the Adriatic passive margin which is the transition zone between the Eastern 
and the Western Alps. In this context, the Avers-Schiefer is considered to be either part of an ancient mélange zone or an accretion prism. Within the orogenic zone, all major tectonic Units have a pronounced easterly axial dip. Consequently, the crustal structure in Eastern Switzerland can be described as a triple junction.

\section{Theoretical Background}

This paper deals with a two-dimensional interpretation of the magnetic response functions which is based on a simplified decomposition model. Therefore all conclusions should be understood as an approximation to the actual threedimensional conductivity distribution. We benefit from closely spaced sites arranged in an array to show an alternative way of presenting and determining the electrical strike when three-dimensionality affects the induction arrows. To do so, we assume that regional currents which originated in

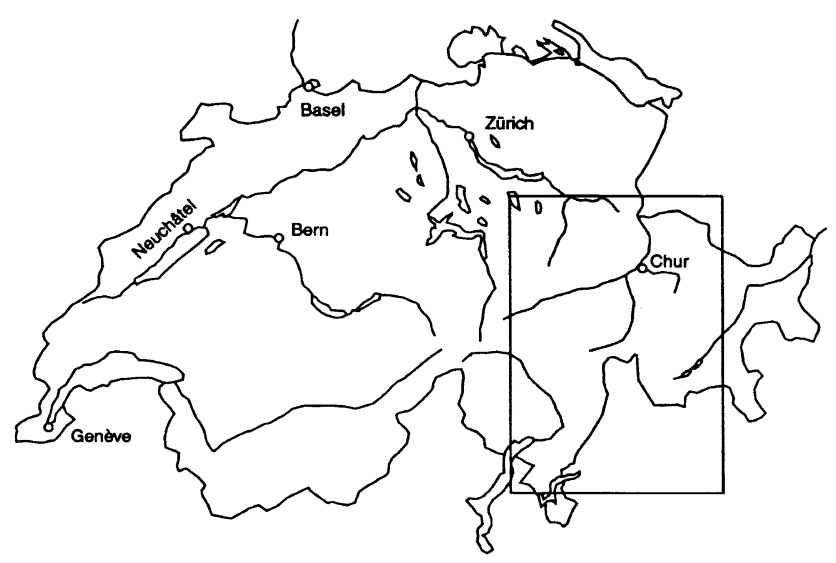

Fig. 1. Location of the investigation area. remote areas are distorted and generate a local anomalous magnetic field that is superimposed on the regional magnetic field. Hence the phase of the anomalous magnetic field equals the phase of the regional electric field. From the observed anomalous magnetic field caused by current channelling at a near surface inhomogeneity we can then derive, from the phase, information about the strike of a regional (hidden) conductive structure. The method of the "Нypothetical Event Analysis" applied to these data can be found in Bailey et al. (1974), Banks and Beamish (1984), Ritter (1996) and Ritter and Banks (1998).

\subsection{Magnetic distortion}

The local superposition of an anomalous magnetic field $\mathbf{B}^{a}$ on the regional magnetic field $\mathbf{B}^{r}$ causes a magnetic distortion. The measured field $\mathbf{B}$ is therefore the sum of the regional and anomalous magnetic fields: $\mathbf{B}^{r}+\mathbf{B}^{a}$. The anomalous field $\left(B_{x}^{a}, B_{y}^{a}, B_{z}^{a}\right)$ is generated by the spatial deviation of uniform regional currents through or around a local anomaly, which is assumed to be much smaller than the skin depth of the investigated period range (Groom and Bailey, 1991). In this case $\mathbf{B}^{a}$ can be seen to be in phase with the regional electric field $\mathbf{E}^{r}$ (Groom, 1988). Similar to the galvanic distortion effect of the regional electric field (Bahr, 1985; Groom, 1988), magnetic distortion of the regional magnetic field can be expressed by a frequency independent real distortion matrix $\underline{\mathbf{D}}$ :

$$
\mathbf{B}^{a}=\underline{\mathbf{D}} \cdot \mathbf{E}^{r} \text {. }
$$

Replacing the regional field $\mathbf{E}^{r}$ by the product of the regional MT impedance $\underline{\mathbf{Z}}^{r}$ and the regional (horizontal) magnetic field $\mathbf{B}^{r}$, we obtain:

$$
\mathbf{B}^{a}=\underline{\mathbf{D}} \underline{\mathbf{Z}}^{r} \cdot \mathbf{B}^{r}
$$

This replacement is only valid, if the local anomaly is sufficiently removed either horizontally or vertically from the regional lateral conductivity boundaries (Ritter, 1996).

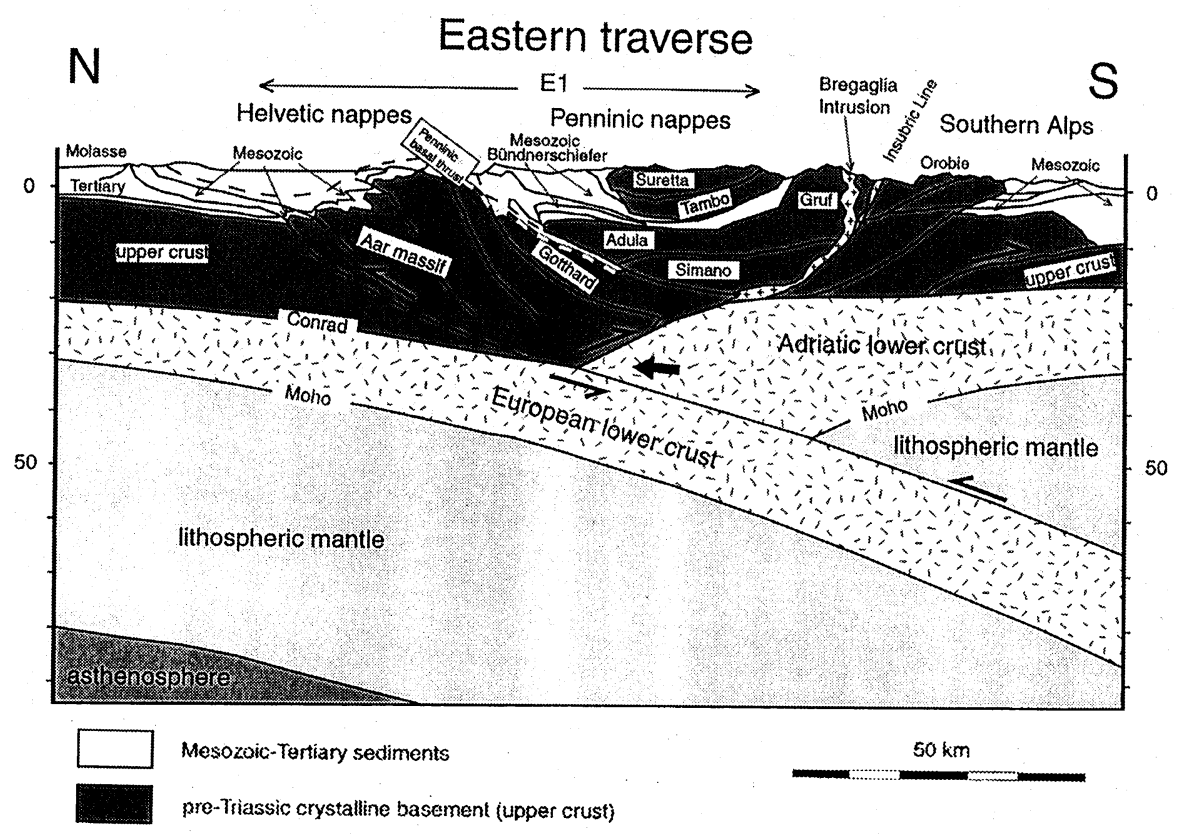

Fig. 2. General geologic profile across the alpine orogen drawn along the trace of the Eastern Traverse but expanded to the Molasse basin and the Po basin (Pfiffner et al., 1997). Line El is part of the European geotraverse. 


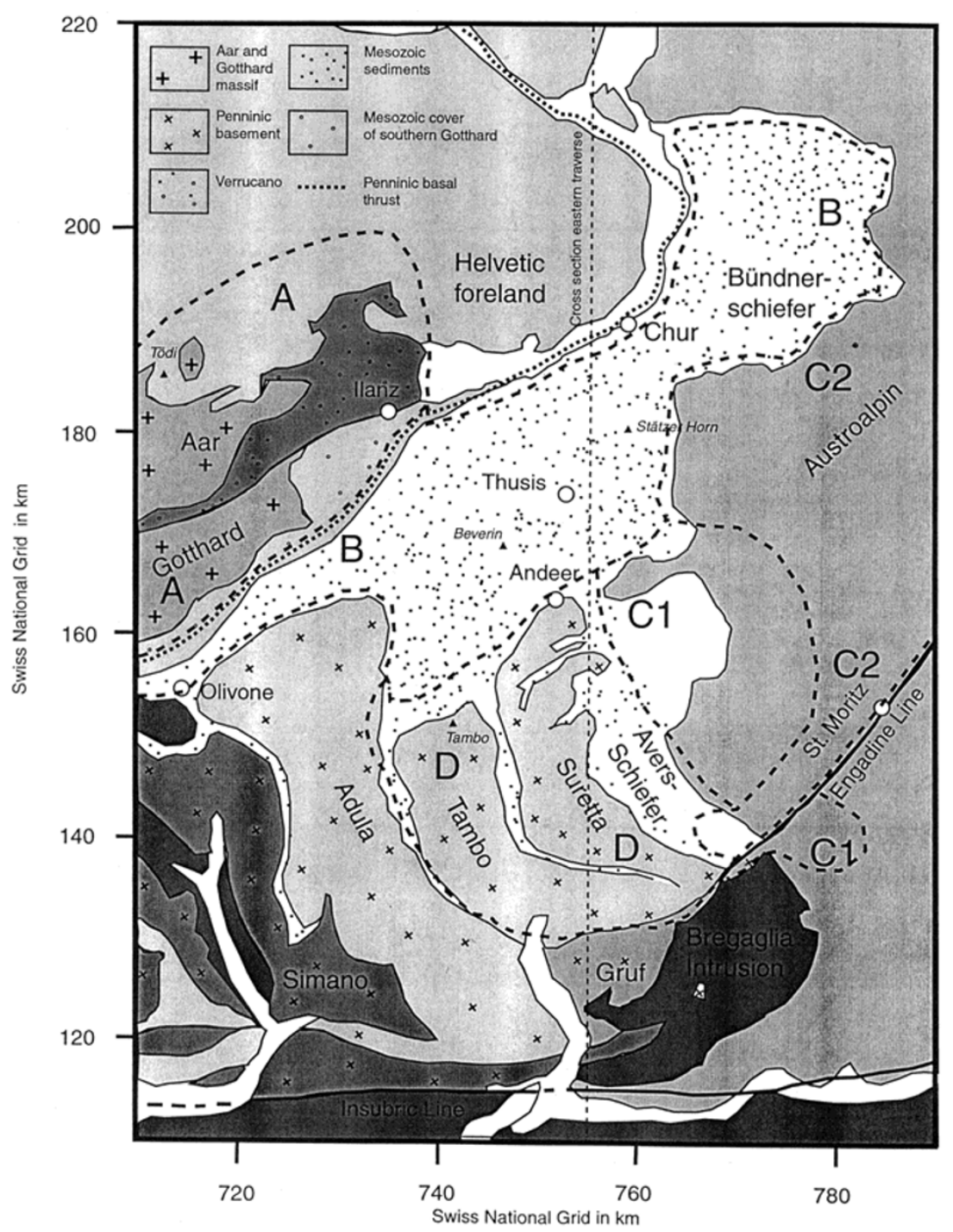

Fig. 3. Simplified tectonic map of the Graubünden with 5 different groups (A-D, dashed lines) of magnetic transfer functions.

Explicitly, if the regional conductivity distribution is twodimensional, the latter equation can be expressed as follows:

$$
\left(\begin{array}{c}
B_{x}^{a} \\
B_{y}^{a} \\
B_{z}^{a}
\end{array}\right)=\left(\begin{array}{ll}
D_{x x} & D_{x y} \\
D_{y x} & D_{y y} \\
D_{z x} & D_{z y}
\end{array}\right) \cdot\left(\begin{array}{cc}
0 & Z_{E} \\
Z_{B} & 0
\end{array}\right)\left(\begin{array}{c}
B_{x}^{r} \\
B_{y}^{r}
\end{array}\right)
$$

with $Z_{E}, Z_{B}$ being the principal impedances in the coordinate system of regional strike $\theta_{r}$ (counter-clockwise). In the coordinates of the measurement we obtain for the vertical component:

$$
\begin{aligned}
B_{z}^{a} & =\left(D_{z x}, D_{z y}\right) \underline{\mathbf{R}}_{\theta_{r}}\left(\begin{array}{cc}
0 & Z_{E} \\
Z_{B} & 0
\end{array}\right) \underline{\mathbf{R}}_{\theta_{r}}^{T}\left(\begin{array}{c}
B_{x}^{r} \\
B_{y}^{r}
\end{array}\right) \\
& \Rightarrow B_{z}^{a}=A^{l} \cdot B_{x}^{r}+B^{l} \cdot B_{y}^{r} .
\end{aligned}
$$

The components $A^{l}$ and $B^{l}$ (see also Eqs. (7) and (8)) of the local transfer function depend only on the regional impedances $Z_{E}, Z_{B}$, the strike of the local inhomogeneity $\theta_{l}$, the strike of the regional structure $\theta_{r}$, their difference $\alpha=\theta_{l}-\theta_{r}$, and a real distortion parameter. In practice, if we measure magnetic variation over an inhomogeneity and if magnetic distortion is present, Eq. (5) substitutes for the commonly used equation by Schmucker (1970):

$$
B_{z}=A \cdot B_{x}+B \cdot B_{y} .
$$

Consequently, the real induction arrows might not indicate the local strike, nor the regional one, but a mixture of both.

\section{Measured Induction Arrows}

The inclusion of the imaginary induction arrows in the examination gives a quantitavive measure for the influence of a three-dimensional conductivity distribution in the investigation area. In Fig. 4 real and imaginary induction arrows for six representative sites are plotted over the period. Using the convention by Schmucker (1970), the real induction arrows point towards a more resistive region, perpendicular to the strike of the lateral resistivity contrast. Furthermore, in the period range of induction, we expect the imaginary arrows to be opposed to the direction of the real arrows. At the period of maximum induction, indicated by the maximum amplitude of the real induction arrows, the imaginary arrows change their sign and direction by $180^{\circ}$. Generally, the measured 

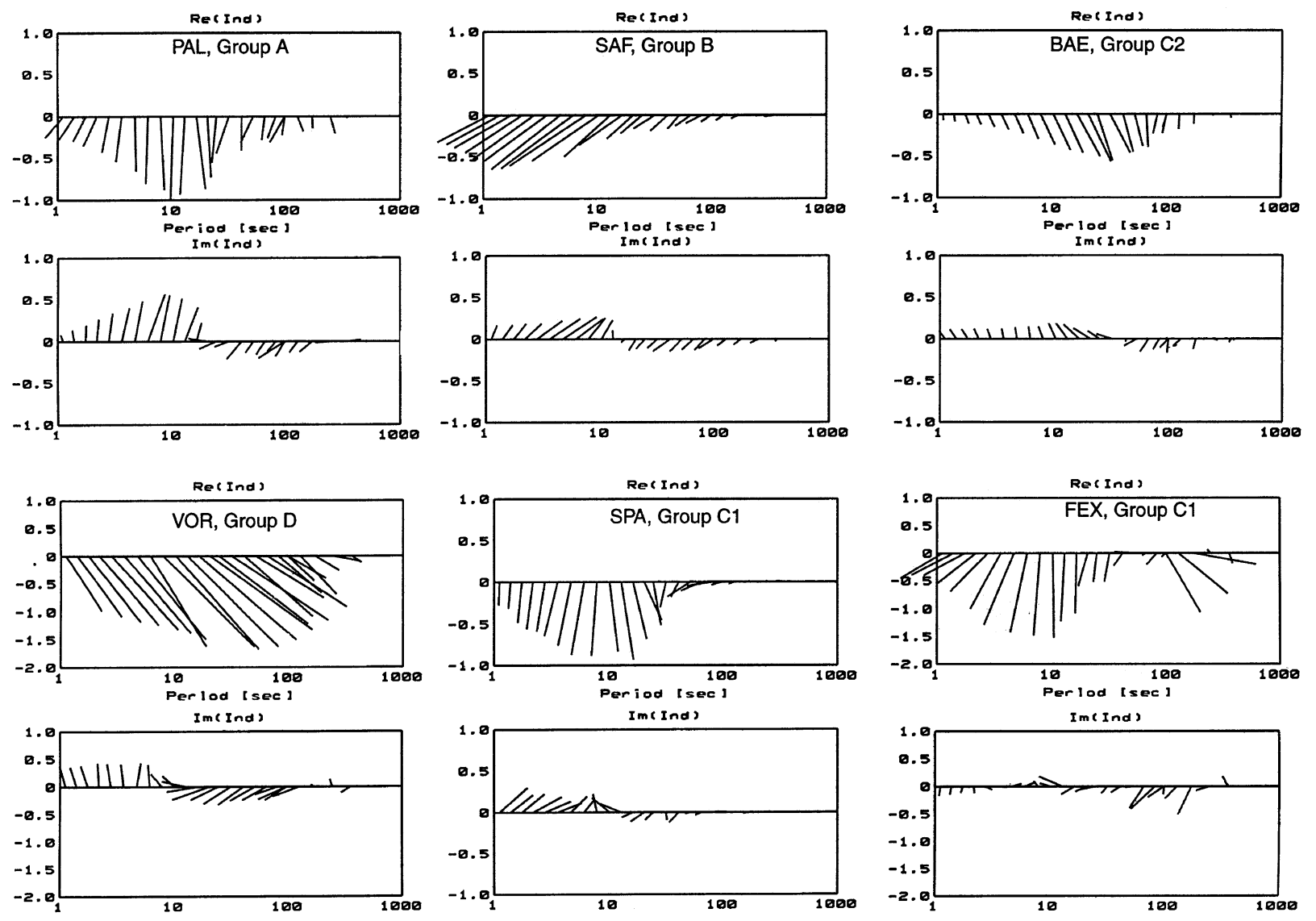

Fig. 4. Real and imaginary induction arrows in Schmucker convention for six representative GDS sites of each group of Fig. 3 over the period.

imaginary induction arrows in Fig. 4 do not significantly show different behaviour to what we would expect for a twodimensional structure. Except for some sites, they do not indicate any influence of other conductors nearby. Figures 5 and 6 show the real induction arrows for the representative periods $T=10 \mathrm{~s}$ and $T=100 \mathrm{~s}$ together with the location of MT/GDS sites and important structural boundaries in the investigation area.

From other induction studies in the Penninic Alps of western Switzerland (Schnegg, 1998) and in the area between the Rhinegraben, the Bohemian Massive and the Central Alps (Berktold, 1978), we know that the predominant direction for real induction arrows is south-eastwards. The Molasse foredeep contributes to this direction (Richards et al., 1982). This sediment basin (1-30 $\Omega \mathrm{m})$ extends over $800 \mathrm{~km}$ from Vienna to Geneva, and is partly overridden and incorporated in the orogenic wedge of the northerly propagating Alpine front (Schlunegger et al., 1997). Geological and geophysical observations confirm that the Bündnerschiefer in the investigation area is situated between Penninic basement slices and the Helvetic massives. The Bündnerschiefer forms an elongated, eastwards plunging ramp with a considerable extension beneath the Austroalpine Units. We consider the unit's resistivities comparable with flysch sediments (20-100 $\Omega \mathrm{m})$ or lower due to high organic carbon content ( $\geq 1 \mathrm{wt} \%)$ (Steinmann, 1994).

Since the Bündnerschiefer can be regarded as a quasi twodimensional structure, the azimuth of the induction arrows should be perpendicular to the strike of this inhomogeneity and point south-east or north-west. However, a rather different behaviour can be observed in the data. Apart from the expected predominant south-eastward direction of the real induction arrows, we also find real induction arrows (Figs. 5 and 6) on the Bündnerschiefer and in adjacent areas of the Helvetic mesozoic cover sediments indicating the main Swiss alpine strike direction $\left(65^{\circ} \mathrm{N}-70^{\circ} \mathrm{N}\right)$. The particular geometry of the tectonical setting leads to the assumption that a flow-around of telluric currents (Rokityansky, 1982) along the surface boundary of the Bündnerschiefer might be responsible for this anomalous directional behaviour of the real induction arrows. The very long induction arrows for the period $T=10 \mathrm{~s}$ together with their directional behaviour indicate that a major lateral contrast in conductivity and geometry is present between the mesozoic sediments and the resistive Penninic basement. In particular, the change of direction next to the site SUF marks the direct and steep contact of both structures. Induced polarization measurements near the site RON (Suana, 1984) obtained surface resistivies for crystalline rocks of the Penninic domain of about $8000 \Omega \mathrm{m}$. Deep geoelectric surveys in the Southern Alps of Orobie revealed the existance of a substratum with high resistivity values of 15000-40000 $\Omega \mathrm{m}$ (Alfano et al., 1994). Similar resistivity values are found by this method to be typical for the exposed mantle rocks of the Ivrea Zone (Blohm, 1977). These values strongly suggests the existence of lateral conductivity contrasts between $10^{\circ}$ and $10^{3}$ and deep penetration 


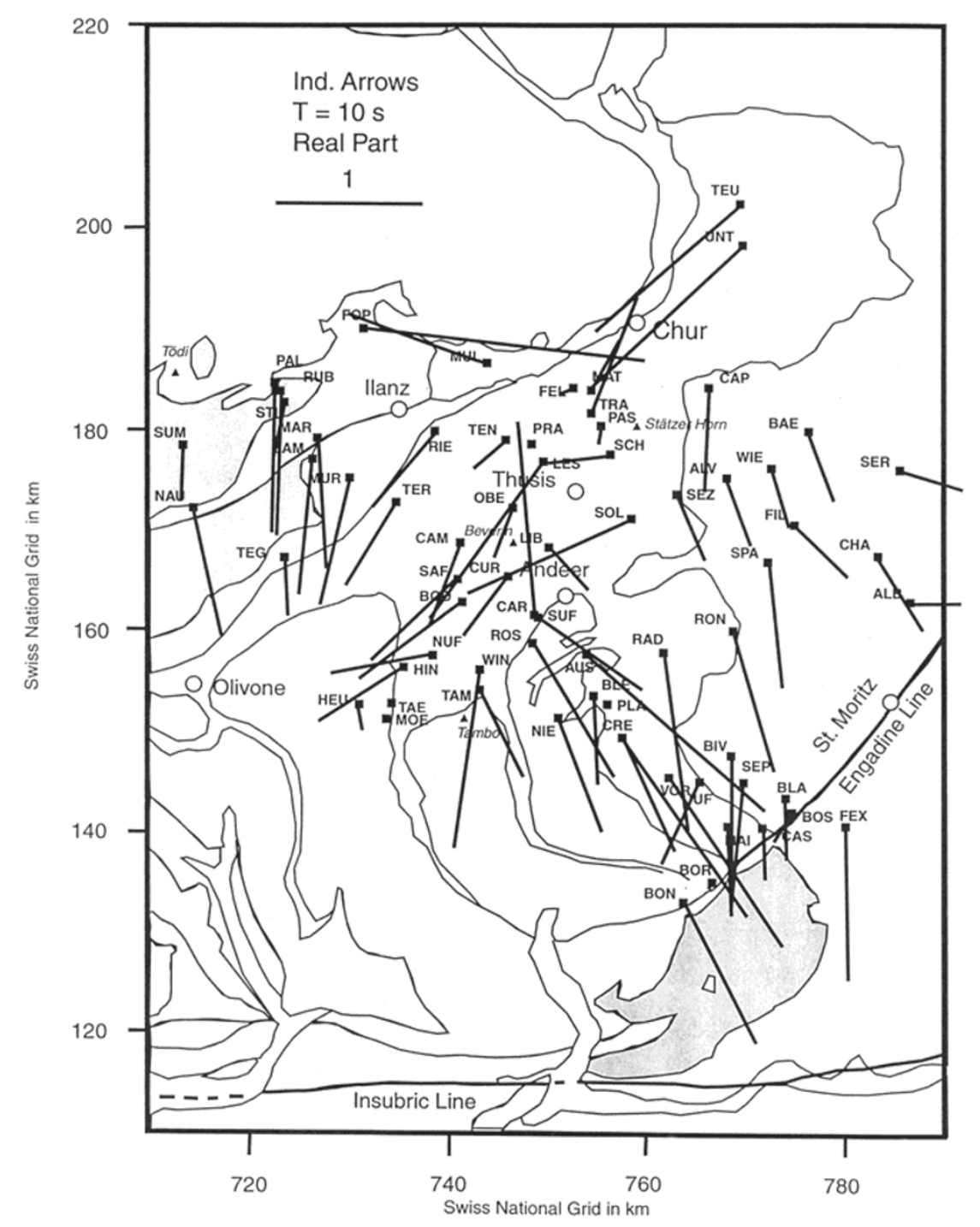

Fig. 5. Real induction arrows in Schmucker convention for the $64 \mathrm{MT} / \mathrm{GDS}$ sites (filled squares) for the period $T=10 \mathrm{~s}$.

depths of the electromagnetic field in the host medium from the mesozoic sediments.

\section{Local and Regional Conductive Structures}

The induction arrow map shows indications for magnetic distortion of GDS data due to a possible current channelling or deflection effect. We do not know the origin of these currents. They may be related to local or regional induction processes. These currents can also be injected from structures elsewhere at the surface of the globe, outside the survey area (Fischer, 1984). Consequently, the investigation area may be too small to account for regional or global effects on the data. To determine wether this is the case, a difference field GDS data set would be in useful. Such a data set would eliminate the influence of a possible regional magnetic field. At present, these data are unavailable.

Magnetic distortion on a local conductive structure depends not only on the lateral conductivity contrast, but also on it's dimension relative to the skin depth of the penetrating fields, the shape and geometry of the inhomogeneity compared to the host rocks (Ritter, 1996). Therefore, in a small conductive body at shallow depth, short period induction processes will evoke a local magnetic field. For longer periods, the same structure can also deviate or concentrate telluric currents originating from a deep regional structure. This will create an additional anomalous static magnetic field on the local response of the inhomogeneity (Ritter, 1996). The Bündnerschiefer and Avers-Schiefer may be local conductive structures, embedded between crystalline rocks, while the Molasse foredeep has to be considered as the dominant regional structure with a possible conductive link to the Bündnerschiefer. The length of the prismatic ramp formed by the Bündnerschiefer is about $80 \mathrm{~km}$, whereas the AversSchiefer is $30 \mathrm{~km}$. The lengths of these structures compared with the estimated skin depths in their host media shown on Table 1 are small for periods longer than $T=10 \mathrm{~s}$ and resistivty values of the host rocks greater than $1000 \Omega \mathrm{m}$. This indicates, that if magnetic distortion is present in the data, the magnetic transfer functions are mostly affected for periods longer than $T=10 \mathrm{~s}$. Furthermore, the whole data set can be distorted if the host rocks reach resistivity values of $100000 \Omega \mathrm{m}$. 


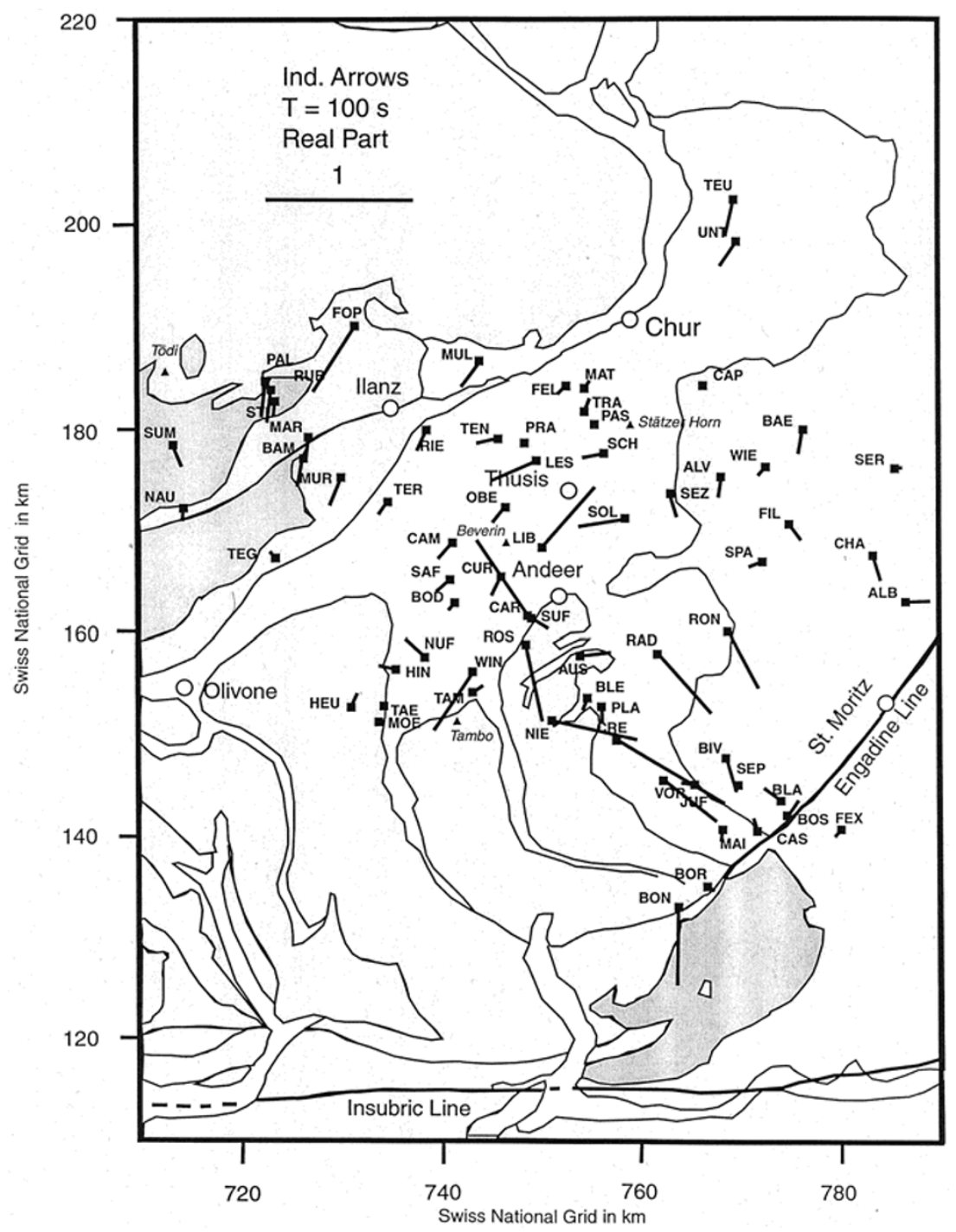

Fig. 6. Real induction arrows in Schmucker convention for the $64 \mathrm{MT} / \mathrm{GDS}$ sites (filled squares) for the period $T=100 \mathrm{~s}$.

Table 1. Skin depths for various periods $T$ and host rock resistivities $\rho$.

\begin{tabular}{lrrr}
\hline$\rho$ in $\Omega \mathrm{m}$ & $T=1 \mathrm{~s}$ & $T=10 \mathrm{~s}$ & $T=100 \mathrm{~s}$ \\
\hline 10 & $1.6 \mathrm{~km}$ & $5 \mathrm{~km}$ & $16 \mathrm{~km}$ \\
100 & $5 \mathrm{~km}$ & $16 \mathrm{~km}$ & $50 \mathrm{~km}$ \\
1000 & $16 \mathrm{~km}$ & $50 \mathrm{~km}$ & $160 \mathrm{~km}$ \\
100000 & $50 \mathrm{~km}$ & $160 \mathrm{~km}$ & $500 \mathrm{~km}$ \\
\hline
\end{tabular}

Schnegg (1998) found a high conductive $(0.2 \Omega \mathrm{m})$ slab in the western Swiss Alps at the base of the Penninic nappes. This slab assumes the shape of the alpine arc. In analogy, we expect a similar or possibly genetically the same structure related to the Penninic basement in eastern Switzerland. In this context, the outcrop of the basal Penninic thrust represents the shape of a possible regional conductive structure into which electric currents might be induced and finally injected into the Bündnerschiefer. We will now focus on the components $A$ and $B$ of the magnetic transfer function so that we can use their significance to delinate the channel geometry and to separate different local structures. To do so, the magnetic transfer functions of each station of the entire data set are grouped according to their behaviour over period, tectonic setting and their amplitudes into five groups shown in Figs. 3 and 7:

1) Group A: Helvetic sediments and basement

2) Group B: Bündnerschiefer, mesozoic sediments

3) Group C1: Austroalpine

4) Group C2: Austroalpine

5) Group D: Avers-Schiefer, mesozoic sediment.

Figure 7 shows plots of the real (RE) and imaginary (IM) components of the magnetic transfer functions for each site $j$ of a group. In the period band $T=10 \mathrm{~s}$ the minimum of the RE $A j$ curves of group $\mathbf{A}$ and $\mathbf{C} 1$ show strong evidence for a current flow in East-West direction. This effect is smaller in group C2. The minimum in RE $A j$ from group $\mathbf{A}$ to $\mathbf{C 1}$ and further to $\mathbf{C 2}$ are shifted towards longer peri- 

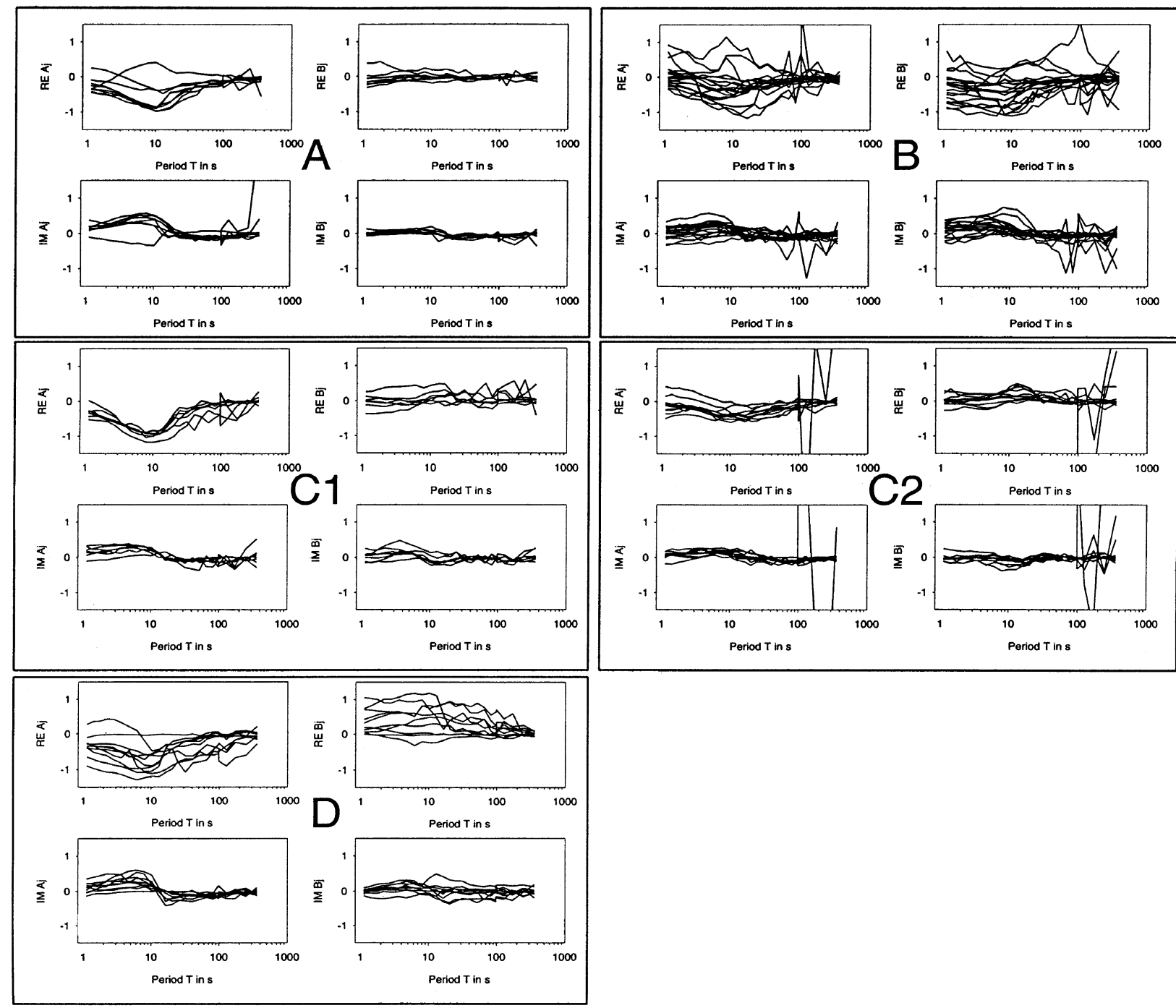

Fig. 7. Real and imaginary parts of the magnetic transfer functions (rotation: $0^{\circ} \mathrm{N}$ ) for groups A-D.

ods. This is a consequence of the eastwards dipping tectonic units. However, the maximum of the RE $B j$ values for the most eastern sites SER, CHA, ALB and BAE of the $\mathbf{C} 2$ group are now influenced by a North-South trend of the electric current. Overall, real and imaginary parts in groups $\mathbf{A}, \mathbf{C 1}$ and C2 show a smoother behaviour over period and comparable amplitudes. In contrast, the magnetic transfer functions of group $\mathbf{B}$ and $\mathbf{D}$ show different behaviour. In Fig. 7 we find the real parts of both components in group B similar in amplitude and over period, whereas in group $\mathbf{D}$ they show inverse sign. The relationship between the magnetic data in group $\mathbf{B}$ and in group $\mathbf{D}$ can be explained in terms of the magnetic distortion theory for two-dimensional structures:

If magnetic distortion is present in the data of one of the groups, we obtain for the components of the local transfer function the following expression (Ritter, 1996).

$$
\begin{aligned}
& A^{l}=D_{z x}^{\prime \prime} \cdot\left[-Z_{E} \cdot \sin \theta_{r} \cdot \cos \alpha+Z_{B} \cdot \cos \theta_{r} \cdot \sin \alpha\right] \\
& B^{l}=D_{z x}^{\prime \prime} \cdot\left[+Z_{E} \cdot \cos \theta_{r} \cdot \cos \alpha+Z_{B} \cdot \sin \theta_{r} \cdot \sin \alpha\right]
\end{aligned}
$$

with: $D_{z x}^{\prime \prime}$ magnetic distortion parameters in measurement coordinates, $Z_{E}, Z_{B}$ principal impedances in the coordinate

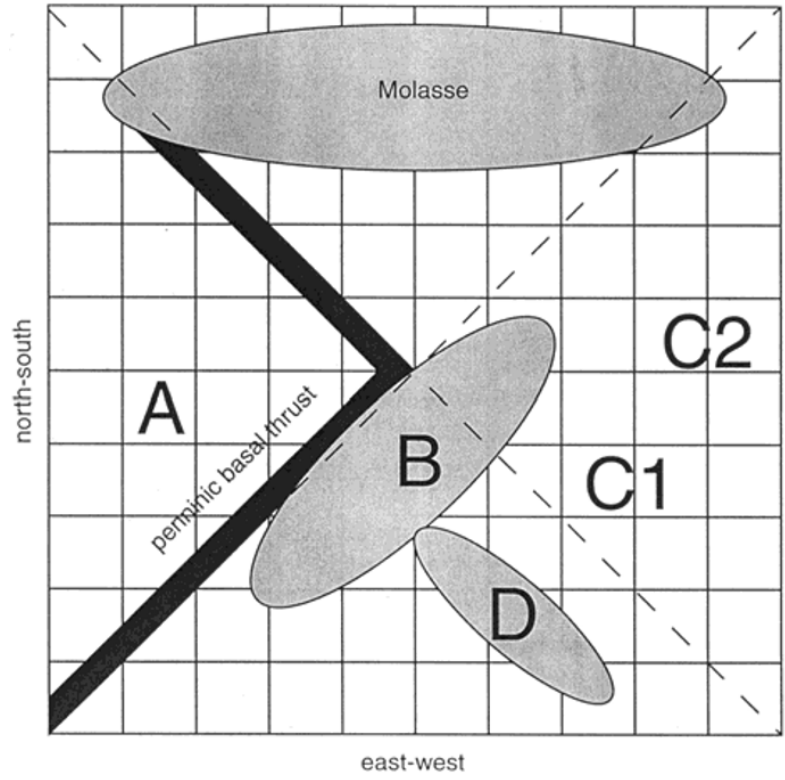

Fig. 8. Possible configuration of local and regional conductive structures in the Eastern Swiss Alps. A-D are groups of magnetic transfer functions of Fig. 7. No scale! 
Table 2. The components of the magnetic transfer functions for different configurations of local and regional conductive structures.

\begin{tabular}{|c|c|c|c|c|}
\hline & $\begin{array}{c}\text { REGIONAL } \\
\text { structure } \\
\text { penninic basal } \\
\text { thrust: } \\
\Theta_{r}=135^{\circ}\end{array}$ & $\begin{array}{c}\text { REGIONAL } \\
\text { structure } \\
\text { Bündnerschiefer B: } \\
\Theta_{r}=135^{\circ}\end{array}$ & $\begin{array}{c}\text { REGIONAL } \\
\text { structure } \\
\text { penninic basal thrust } \\
\text { Avers-Schiefer D: } \\
\Theta_{r}=135^{\circ}\end{array}$ & $\begin{array}{c}\text { REGIONAL } \\
\text { structure } \\
\text { Molasse basin: } \\
\Theta_{r}=90^{\circ}\end{array}$ \\
\hline $\begin{array}{l}\mathbf{L} \\
\mathbf{O} \\
\mathbf{C} \\
\mathbf{A} \\
\mathbf{L}\end{array}$ & $\begin{array}{l}\Theta_{r}=135^{\circ}, \Theta_{l}=135^{\circ} \\
\alpha=0^{\circ} \\
A^{l}=-D_{z x}{ }^{\prime \prime} \cdot Z_{E} / \sqrt{2} \\
B^{l}=-D_{z x}{ }^{\prime \prime} \cdot Z_{E} / \sqrt{2} \\
\Rightarrow A^{l}=B^{l}\end{array}$ & $\begin{array}{c}\text { Regional } \\
\text { Structure } \\
\text { Bündnerschiefer } \\
\uparrow \\
\text { Local } \\
\text { Structure } \\
\text { Bündnerschiefer }\end{array}$ & $\begin{array}{l}\Theta_{r}=45^{\circ}, \Theta_{l}=135^{\circ} \\
\alpha=90^{\circ} \\
A^{l}=D_{z x}^{\prime \prime} \cdot Z_{B} / \sqrt{2} \\
B^{l}=D_{z x}^{\prime \prime} \cdot Z_{B} / \sqrt{2} \\
\Rightarrow A^{l}=B^{l}\end{array}$ & $\begin{array}{l}\Theta_{r}=90^{\circ}, \Theta_{l}=135^{\circ} \\
\alpha=45^{\circ} \\
A^{l}=-D_{z x}{ }^{n} \cdot Z_{E} / \sqrt{2} \\
B^{l}=+D_{z x}{ }^{\prime \prime} \cdot Z_{B} / \sqrt{2} \\
\Rightarrow A^{l}=B^{l} \text { for } Z_{E}=-Z_{B}\end{array}$ \\
\hline $\begin{array}{l}\mathbf{L} \\
\mathbf{O} \\
\mathbf{C} \\
\mathbf{A} \\
\mathbf{L}\end{array}$ & $\begin{array}{l}\Theta_{r}=135^{\circ}, \Theta_{l}=45^{\circ} \\
\alpha=90^{\circ} \\
A^{l}=-D_{z x}{ }^{\prime \prime} \cdot Z_{B} / \sqrt{2} \\
B^{l}=+D_{z x}{ }^{\prime \prime} \cdot Z_{B} / \sqrt{2} \\
\Rightarrow A^{l}=-B^{l}\end{array}$ & $\begin{array}{l}\Theta_{r}=135^{\circ}, \Theta_{l}=45^{\circ} \\
\alpha=90^{\circ} \\
A^{l}=-D_{z x}{ }^{\prime \prime} \cdot Z_{B} / \sqrt{2} \\
B^{l}=+D_{z x}{ }^{\prime \prime} \cdot Z_{B} / \sqrt{2} \\
\Rightarrow A^{l}=-B^{l}\end{array}$ & $\begin{array}{c}\text { Regional } \\
\text { Structure } \\
\text { Avers-Schiefer } \\
\downarrow \\
\text { Local } \\
\text { Structure } \\
\text { Avers-Schiefer }\end{array}$ & $\begin{array}{l}\Theta_{r}=90^{\circ}, \Theta_{l}=45^{\circ} \\
\alpha=-45^{\circ} \\
A^{l}=-D_{z x}{ }^{\prime \prime} \cdot Z_{E} / \sqrt{2} \\
B^{l}=-D_{z x}{ }^{\prime \prime} \cdot Z_{B} / \sqrt{2} \\
\Rightarrow A^{l}=-B^{l} \text { for } Z_{E}=-Z_{B}\end{array}$ \\
\hline
\end{tabular}

system of regional strike $\theta_{r}, \alpha=\theta_{l}-\theta_{r}$ and $\theta_{l}$ local strike (angles counted counter-clockwise).

This leads to special cases due to the geometric configuration of local and regional conductive structures and their spatial constellation as shown in Table 2 and in the simple model in Fig. 8.

1) geometric configuration

Regional strike parallel or perpendicular to local strike: $\alpha=0^{\circ}$ :

$$
\begin{aligned}
A^{l} & =D_{z x}^{\prime \prime} \cdot\left[-Z_{E} \cdot \sin \theta_{r}\right] \\
B^{l} & =D_{z x}^{\prime \prime} \cdot\left[+Z_{E} \cdot \cos \theta_{r}\right] .
\end{aligned}
$$

$\underline{\alpha=90^{\circ}}:$

$$
\begin{aligned}
& A^{l}=D_{z x}^{\prime \prime} \cdot\left[+Z_{B} \cdot \cos \theta_{r}\right] \\
& B^{l}=D_{z x}^{\prime \prime} \cdot\left[+Z_{B} \cdot \sin \theta_{r}\right] .
\end{aligned}
$$

\section{2) spatial constellation}

Since we do not know which of the introduced structures of the area is local or regional, we listed the respective combinations of parameters for regional strike directions of $\theta_{r}=45^{\circ}$ and $135^{\circ}$ in Table 2. In addition, the East-West orientated $\left(\alpha=45^{\circ}\right)$ Molasse basin is also shown. The Table provides a series of permutations which combine regional and local conductive structures to generate the observed relationship between the real transfer functions of Group $\mathbf{B}$ and $\mathbf{D}$.

The Molassse basin is the only case which depends on both principal impedances $Z_{E}$ and $Z_{B}$. This structure can be responsible for the anomalous direction of the real induction arrows on the Bündnerschiefer only if the regional conductivity distribution is one-dimensional $\left(Z_{E}=-Z_{B}\right)$. However, we should not exclude this basin to be the origin of currents injected into the Penninic sediments, since the overall dominating azimuth for real induction arrows in the central Alps seems to be caused by its sedimentary filling. If the Penninic basal thrust represents a $\mathrm{L}$ shaped regional conductive structure as shown in Fig. 8, it has the ability to cause the observed effects upon the magnetic transfer functions of group B as well as for group D. If we regard the Bündnerschiefer as a regional conductive structure and the Avers-Schiefer as a local conductive structure, we can explain the effect on the magnetic field in group $\mathbf{D}$ but not in group $\mathbf{B}$, and vice versa. But we have to point out that the Avers structure does not exceed the required longitudinal extension to allow currents be induced in the observed period band and presumably for much longer periods. The continuation of the Bündnerschiefer beneath Middle Penninic, South Penninic and Austroalpine units to the East is generally considered. From these observations following conclusions can be made:

- Any superposition of conductive structures of regional extension with an azimuth of a multiple of $45^{\circ} \mathrm{N}$ can cause the magnetic distortion in GDS data in the investigation area.

- If the conductivity distribution in the Molasse basin is one-dimensional, the current channelling effect of the Bündnerschiefer (with $\alpha=45^{\circ}$ ) can be responsible for distortion effects in the data.

- The superposition of point 1 and point 2 can cause the observed induction arrow pattern.

- The Avers-Schiefer are local, the Bündnerschiefer are regional inhomogeneities.

\section{Hypothetical Event Analysis}

To verify the validity of the model obtained in the previous section, the method of Hypothetical Event Analysis (HEA) has been applied to the measured data set. This method uses a hypothetical uniform external horizontal field $\mathbf{B}_{h}^{*}$ of specified polarization $\vartheta^{*}$ to calculate a predicted vertical magnetic 


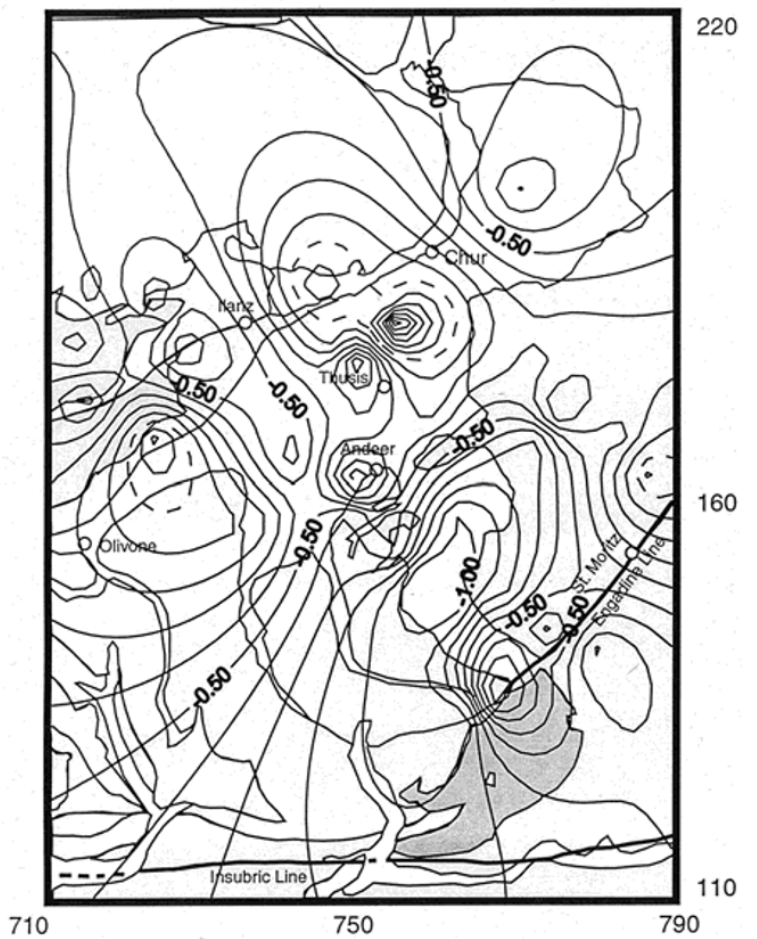

(a)

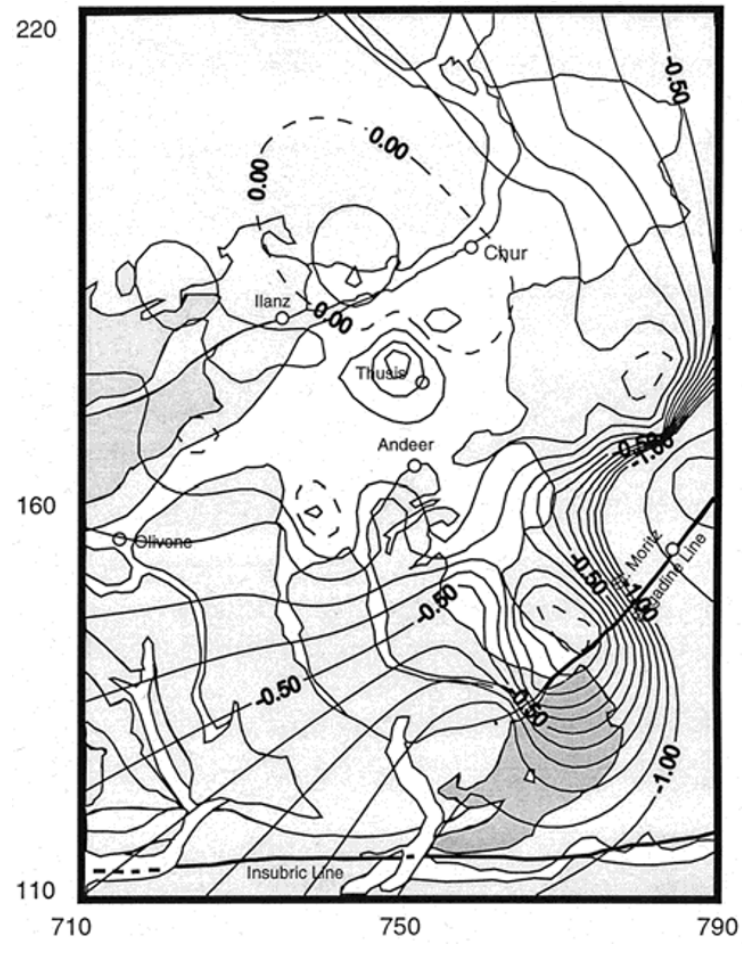

(b)

Fig. 9. Hypothetical event map of the anomalous vertical magnetic field: real part, Azimuth of regional field relative to magnetic North: $0^{\circ}$. Period $T=4.7 \mathrm{~s}(\mathrm{a})$, Period $T=126 \mathrm{~s}$ (b). Amplitude of horizontal field: $1 \mathrm{nT}$, phase of the horizontal field: $0^{\circ}$.

field $B_{z}^{p}$ for all stations in a data array. All variations in the generated predicted map are of internal origin and are caused by channelling effects or induction (Bailey, 1974). From a calculated predicted map of $B_{z}^{p}$ for each period $T$ and different polarizations $\vartheta^{*}$, we try to infer the anomalous current distribution and therefore to analyse the three-dimensional conductivity structure with depth:

$$
B_{z}^{p}=A \cdot B_{x}^{*}+B \cdot B_{y}^{*} .
$$

In practice, a horizontal field of $1 \mathrm{nT}$ is chosen to generate maps of the anomalous field (Bailey, 1974):

$$
B_{z}^{p}=(A, B)\left(\begin{array}{c}
1 \cdot \cos \vartheta^{*} \\
1 \cdot \sin \vartheta^{*}
\end{array}\right) .
$$

Consequently, if the hypothetical event is polarized in the East or North direction relative to the magnetic North with zero phase, the predicted value $B_{z}^{p}$ reduces to one of the principal magnetic response functions:

$$
\begin{gathered}
B_{z}^{p}=A \text { for } \vartheta^{*}=0^{\circ} \\
B_{z}^{p}=B \text { for } \vartheta^{*}=90^{\circ} .
\end{gathered}
$$

The polarization in the North direction should drive a current in East-West direction, whereas an eastwards polarized magnetic field drives currents in the North-South direction through the area of interest.

The simplified analysis of the magnetic transfer function in the previous section already implied the main strike directions for the structures to be either $90^{\circ} \mathrm{N}, 45^{\circ} \mathrm{N}$ or $135^{\circ} \mathrm{N}$. In Figs. 9, 10 and 11 we used polarizations according to these directions to generate HEA maps of the real part of the magnetic field for the periods $T=4.7 \mathrm{~s}$ and $T=126 \mathrm{~s}$. Current concentration are indicated by the spatial gradients $( \pm 1 \mathrm{nT})$ in the vertical magnetic field. Figures 9(a) and 9(b) show the effect of a North-South polarized horizontal magnetic field, that drives an electric current in East-West direction. In Figs. 10(a) and 10(b) we generate a current flow along the strike of the Bündnerschiefer (North-East), whereas in Figs. 11(a) and 11(b) the direction of the current flow is South-East.

Regardless of the polarization angle, we find, for the short periods a complex pattern of anomalies mainly generated on the mesozoic sediments. On the other hand, the Helvetic Domain, the Penninic basement slices and the Austroalpine Units are almost free from channelling effects. Significantly, the HEA maps for $T=126 \mathrm{~s}$ contrasts with the previous cases and show a dominating anomaly under the Austroalpine Units. The anomaly forms a wedge and is strongly associated with the strike of the Engadine Line (strike-slip fault), whereas the anomalies for the shorter periods on the Penninic sediments have virtually disappeared.

From the model in Fig. 8, we would expect an anomaly pattern which is correlated with the basal Penninic thrust and the mesozoic sediments Bündnerschiefer and Avers-Schiefer. In fact, the HEA map for a magnetic field with an azimuth of $135^{\circ} \mathrm{N}$ and $T=4.7 \mathrm{~s}$ (Fig. 10(a)) produces the most straight forward current channelling system. Here we find a strong anomaly in front of the Tambo and Suretta nappes which deviates into the Avers-Schiefer and stops at the end of the Engadine Line. Another current channelling effect might be associated with the Verrucano, which separates the Aar and 


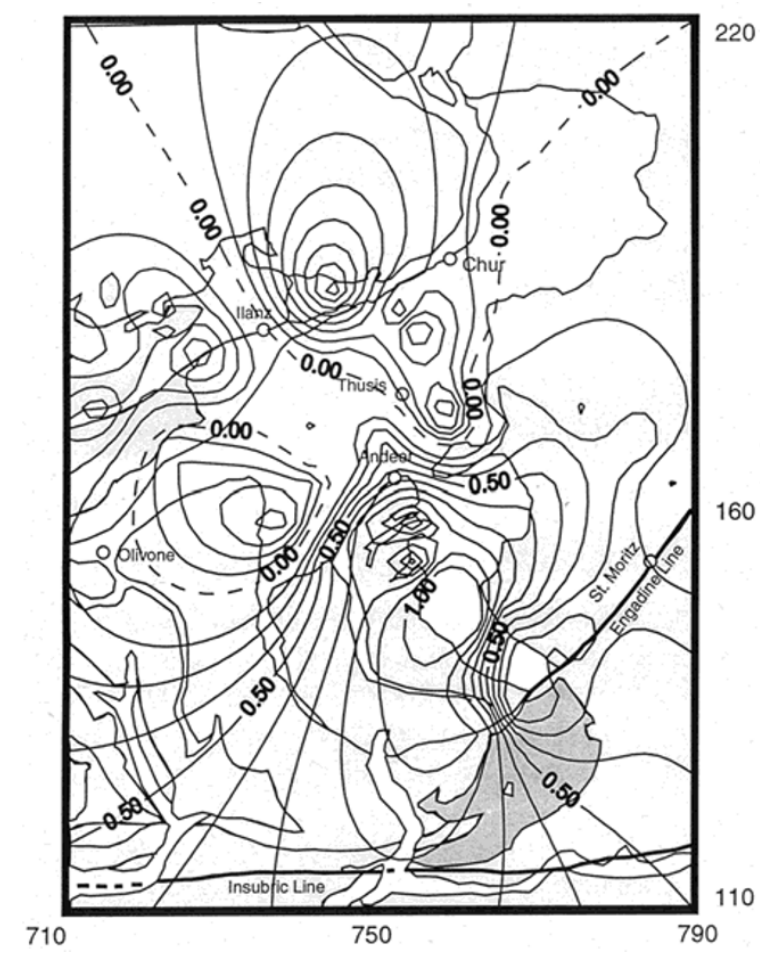

(a)

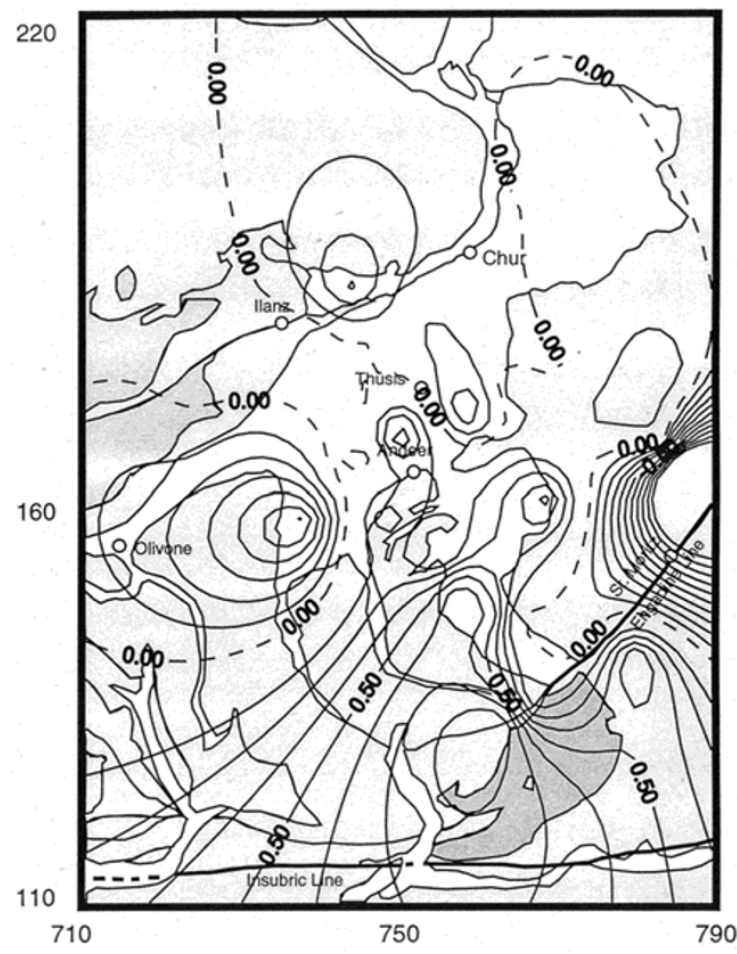

(b)

Fig. 10. Hypothetical event map of the anomalous vertical magnetic field: real part, Azimuth of regional field relative to magnetic North: $45^{\circ}$. Period $T=4.7 \mathrm{~s}$ (a), Period $T=126 \mathrm{~s}$ (b). Amplitude of horizontal field: $1 \mathrm{nT}$, phase of the horizontal field: $0^{\circ}$.

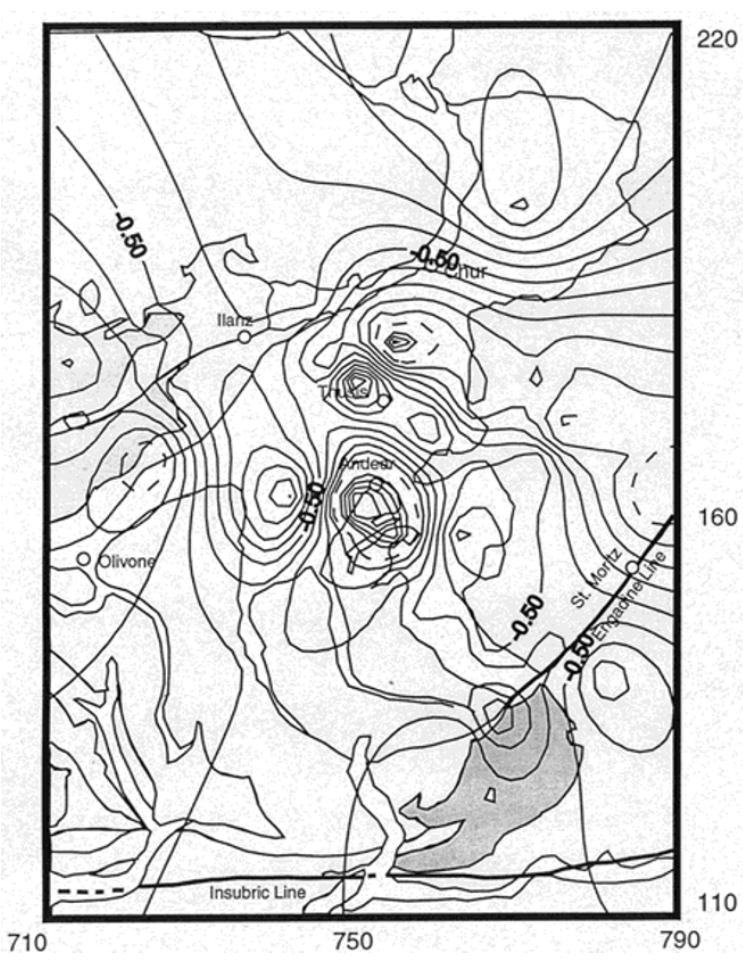

(a)

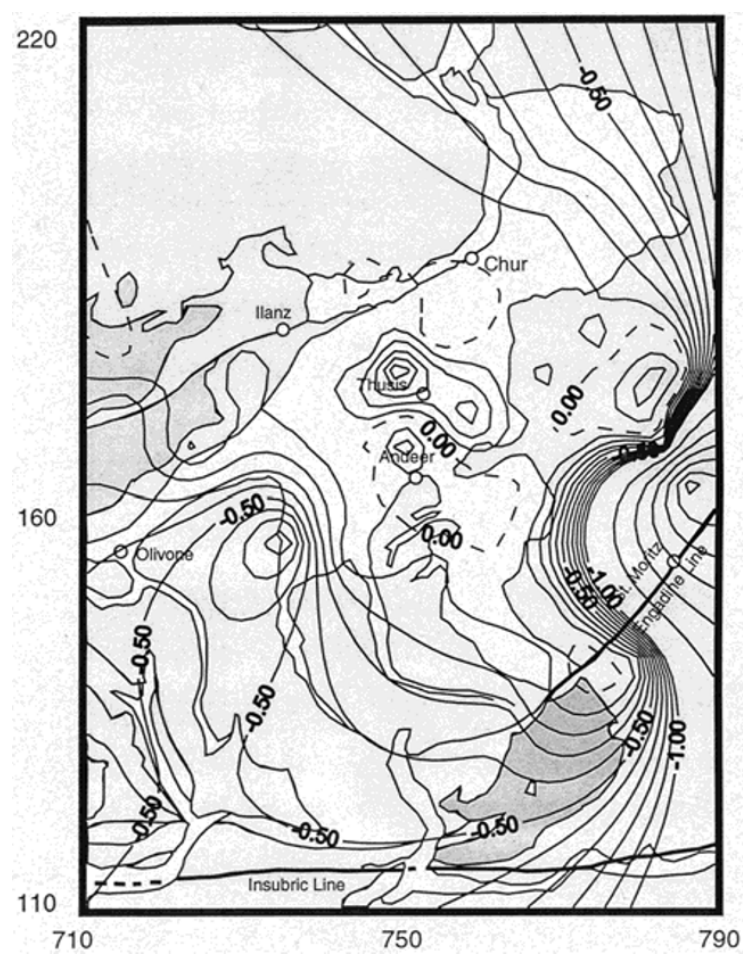

(b)

Fig. 11. Hypothetical event map of the anomalous vertical magnetic field: real part, Azimuth of regional field relative to magnetic North: $135^{\circ}$. Period $T=4.7 \mathrm{~s}(\mathrm{a})$, Period $T=126 \mathrm{~s}(\mathrm{~b})$. Amplitude of horizontal field: $1 \mathrm{nT}$, phase of the horizontal field: $0^{\circ}$. 


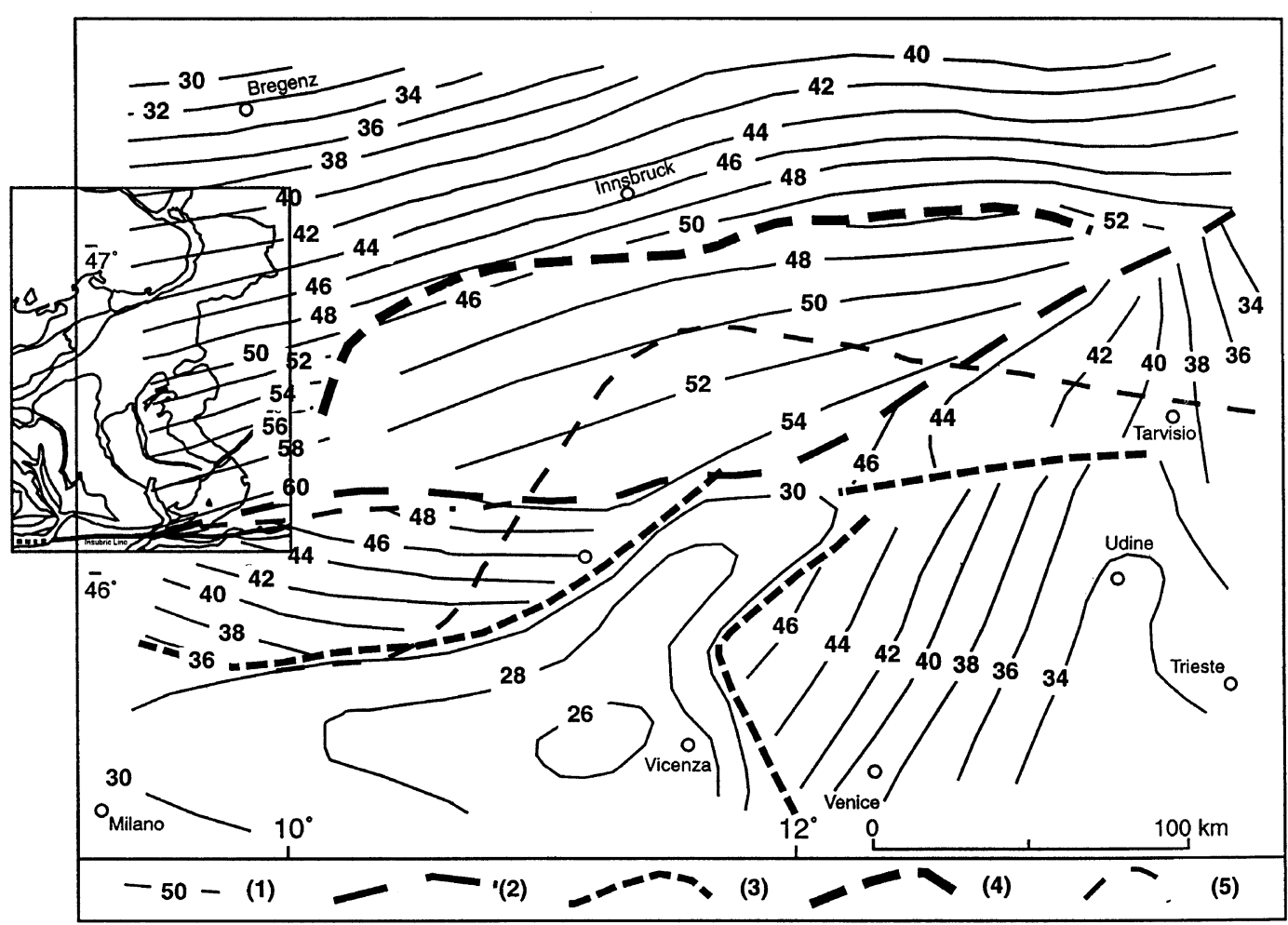

Fig. 12. Depth contour lines 1) of the Moho boundary $(\mathrm{km})$ inclusive the location of the investigation area. The major near vertical offsets and overriding fronts are plotted. 2) Moho overriding front; 3) offset >10 km; 4) offset $<10 \mathrm{~km}$; 5) Insubric Line. After Cassinis et al. (1997).

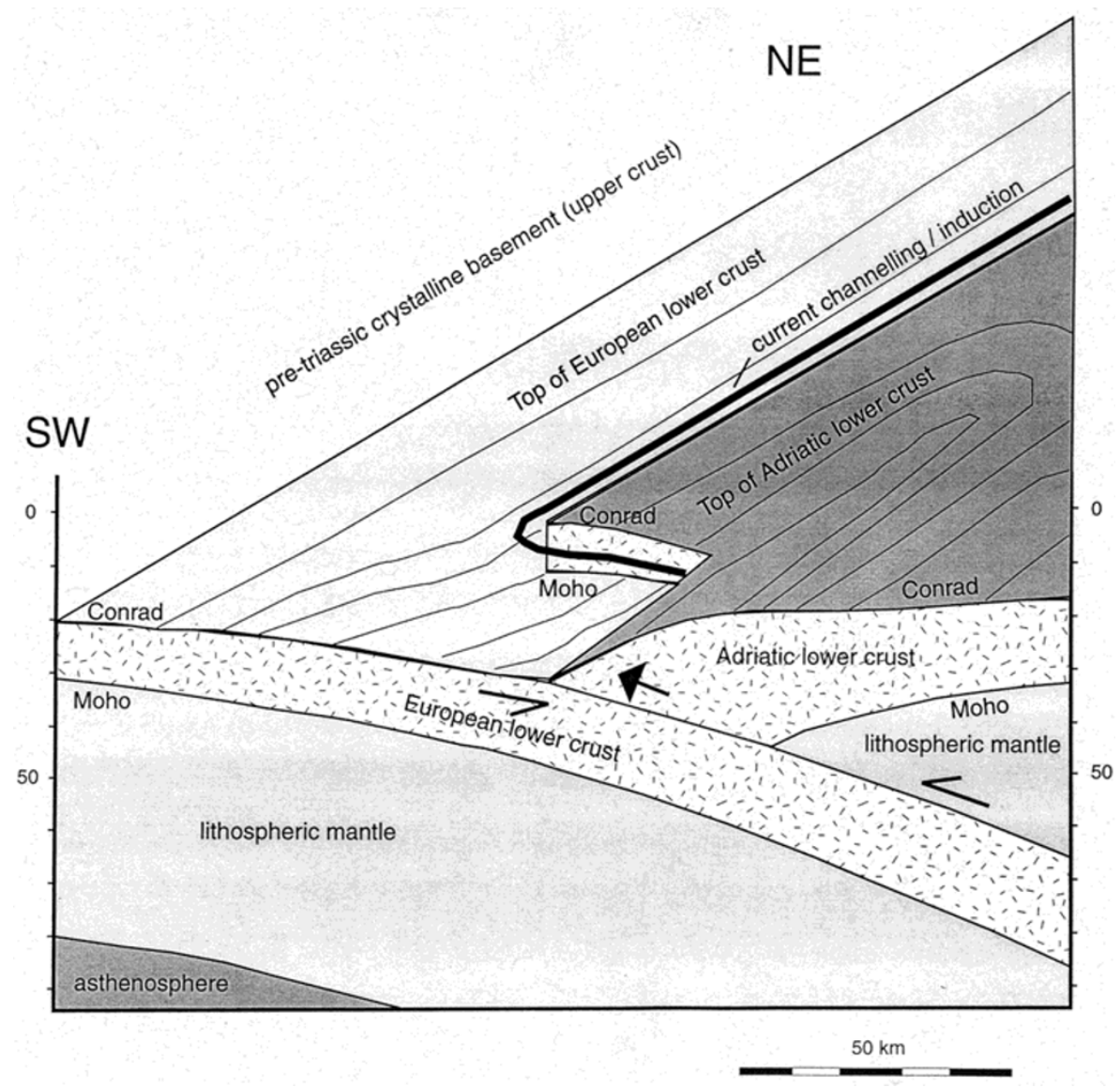

Fig. 13. Simplified model of the top of lower crust from the trace of the Eastern traverse (Penninic Domain) to the North-East (Austroalpine) showing the indentation by the Adriatic plate and the presumed current channelling/ induction. The upper crust is stripped off. After Pfiffner et al. (1997) and Cassinis et al. (1997). 
Gotthard massive. The anomaly to the North-East of Thusis is probably due to internal structures of the Bündnerschiefer. However, the current system in this pattern moderately reflects the boundaries of the magnetic transfer functions found for the groups A-D.

\section{Conclusion}

The HEA shows a spatial decoupling of induction processes with depth. For short periods $(T=1-10 \mathrm{~s})$, induction and/or current channelling is related to the mesozoic sediments and their internal inhomogeneities. For periods longer than $T=126 \mathrm{~s}$, induction and/or current channelling is limited to the Austroalpine and Penninic basement. The model of a L shaped structure associated with the basal Penninic thrust cannot be confirmed. A structural conductivity anomaly with a strike of $45^{\circ} \mathrm{N}$ respectively $135^{\circ} \mathrm{N}$ is found at depth. Thus, the conductivity distribution in this part of the Alps is strongly three-dimensional. The correlation of the deep conductor with the Engadine Line implies that this strike slip fault is of lower crustal origin.

\section{Discussion}

Little is known about the deep structure of the transition zone from the Western to the Eastern Alps. Recent seismic refraction studies, however, revealed a region partially lacking of lower crustal reflectivity. This is probably related to strong energy scattering along complex deformation structures (Pfiffner et al., 1997). Figure 12 (after Cassinis, 1997) shows depth contour lines of the Moho boundary derived from seismic and gravity data together with our investigation area (box). Line (4) represents a strip of an Moho offset $(<10$ $\mathrm{km})$ due to a possible Adriatic indenter which forms in its western part a wedge bearing the geometric properties necessary to explain the revealed deep conductivity anomaly. Since their data resolutions is quite poor, we can shift this structure some kilometers to the West. In our model shown in Fig. 13, this Moho offset is caused by a strip of peeled Adriatic lower crust/mantle overlaying the European lower crust (stacked lithosphere). As a fact of this offset, good conductive Adriatic lower crust lies side by side with resistive European upper crust, creating a sharp lateral conductivity contrast. In this context, a North-South component of current flow found by Berktold $(1974,1976)$ south of the Tauern might be associated to the same regional anomaly.

Acknowledgments. This work was supported by Swiss National Science Foundation grants 20-47135.

\section{References}

Alfano, L., G. Lorenzoni, C. Melachi, M. Mochi, G. Nuttini, F. Pirera, and M. E. Soffientini, A deep geoelectrical survey in the Southern Central Alps, Ann. Geofisica, XXXVII(5), 1185-1198, 1994.

Arora, B. R. and A. Adam, Anomalous directional behaviour of induction arrows above elongated conductive structures and its possible causes, Phys. Earth Planet. Inter., 74, 183-190, 1992.

Bahr, K., Magnetotellurische Messungen des Elektrischen Widerstandes der Erdkruste und des oberen Mantels in Gebieten mit Lokalen und Regionalen Leitfähigkeitsanomalien, Ph.D. Thesis, G. August Univ., Göttingen, 1985

Bahr, K., Interpretation of the magnetotelluric impedance tensor: regional induction and local telluric distortion, J. Geophys., 62, 119-127, 1988.

Bailey, R., R. Edwards, G. Garland, R. Kurtz, and D. Pitcher, Electrical conductivity studies over a tectonical active area in Eastern Canada, $J$.
Geomag. Geoelectr., 26, 125-146, 1974.

Banks, R. J. and D. Beamish, Local and regional induction in the British Isles, Geophys. J. R. astr. Soc., 79, 539-553, 1984.

Berktold, A., Erdmagnetische Tiefensondierung in Süddeutschland und in den Alpen, in Elektromagnetische Tiefenforschung, edited by A. Berktold, pp. 58-70, Deutsche Geophysikalische Gesellschaft, Grafrath/Bayern, 1974.

Berktold, A., On the distribution of the electrical conductivity in the area between the Rhinegraben, the Bohemian Massive and the Central Alps, Acta Geodaet., Geophys. and Montanist. Acad. Sci. Hung. Tomus, 13(34), 437-440, 1978.

Berktold, A., M. Beblo, and K. Kemmerle, On the distribution of the electric conductivity below the Eastern Alps, Geol. Rundschau, 65(2), 715-732, 1976 (reprint).

Blohm, E.-K., Ultrabasisches Mantelmaterial: Tiefengeoelektrik beim Ultramafitit-Körper von Finero, 10 pp., Endbericht zur DFG-Sachbeihilfe Bl 131/1. Archiv BGR/Nlfb 77 855, Hannover, 1977.

Blundell, D., R. Freemann, and St. Müller, (eds.), A Continent Revealed. The European Geotraverse, 275 pp., Cambridge University Press, Cambridge, 1992.

Cassinis, R., F. Federici, A. Galmozzi, and S. Scarascia, A three-dimensional gravity model of crustal structure in the Central-Eastern Alpine sector, Ann. Geofisica, XL(5), 1095-1107, 1997.

Coward, M. and D. Dietrich, Alpine tectonics-an overview, in Alpine Tectonics, edited by M. Coward, D. Dietrich, and R. G. Park, 45, pp. 1-29, Geol. Soc. London Spec. Publ., 1989.

Fischer, G., The North Pyrenean magnetic anomaly re-examined, Ann. Geophysicae, 2(2), 181-186, 1984.

Groom, R. W., The effects of inhomogeneities on magnetotellurics, Ph.D. Thesis, Univ. Toronto, 1988.

Groom, R. W. and R. C. Bailey, Analytic investigation of the effect of nearsurface 3D galvanic scatters on MT tensor decomposition, Geophysics, 56, 496-518, 1991.

Jones, A. G. and R. W. Groom, Strike-angle determination from the magnetotelluric impedance tensor in the presence of noise and local distortion: rotate at your peril!, Geophys. J. Int., 113, 524-534, 1993.

Pfiffner, O. A. and L. Hitz, Geologic interpretation of the seismic profiles of the eastern traverse (lines E1-E3, E7-E9): Eastern Switzerland, in Deep Structure of the Swiss Alps, edited by O. A. Pfiffner, P. Lehner, P. Heitzmann, St. Mueller, A. Steck, 380 pp., Birkhäuser Verlag, Basel, 1997.

Richards, M. L., U. Schmucker, and E. Steveling, Electrical conductivity in the Urach geothermal area, a geomagnetic induction study using pulsations, in The Urach Geothermal Project (Swabian Alb Germany), edited by H. Ralph, pp. 301-311, Schweitzerbart'sche Verlagsbuchhandlung, Stuttgart, 1982.

Ritter, P., Separation of local and regional information in geomagnetic response functions using hypothetical event analysis, Ph.D. Thesis, University of Edinburgh, Edinburgh, 1996.

Ritter, P. and R. Banks, Separation of local and regional information in distorted GDS response functions by hypothetical event analysis, Geophys. J. Int., 135, 923-942, 1998.

Rokityansky, I., Geoelectromagnetic Investigation of the Earth's Crust and Mantle, 381 pp., Springer Verlag, Berlin, 1982.

Schlunegger, F. R., A. Matter, D. W. Burbank, and E. M. Klaper, Magnetostratigraphic constraints on relationships between evolution of the central Swiss Molasse basin and Alpine orogenic events, Bull. Geol. Soc. Am., 109, 225-241, 1997

Schmid, S. M., O. A. Pfiffner, N. Froitzheim, G. Schönborn, and E. Kissling, Geophysical-geological transect and tectonic evolution of the SwissItalien Alps, Tectonics, 15(5), 1036-1064, 1996.

Schmucker, U., Anomalies of geomagnetic variations in the southwestern United States, Bull. Scripps. Inst. Oceanogr., 13, pp. 1-165, Univ. Calif., 1970.

Schnegg, P.-A., The magnetotelluric survey of the Penninic Alps of Valais, Matériaux pour la Géologie de la Suisse, 32, 76 pp., Swiss Geophysical Commission, 1998.

Steinmann, M., Ein Beckenmodell für das Nordpenninikum der Ostschweiz., Jb. Geol. B.-A, 137(4), 675-721, 1994.

Suana, M., Die Manganerzlagerstätten von Tinizong (Oberhalbstein, Graubünden), Beiträge zur Geologie der Schweiz, 64, 92 pp., Schweizerische Geotechnische Kommission, 1984.

M. Gurk (e-mail: marcus.gurk@geol.unine.ch) 